\title{
Analisis Implementasi Kesehatan dan Keselamatan Kerja Pada Pembangunan Gedung Perpustakaan Kabupaten Aceh Jaya
}

\author{
Sustria Sari ${ }^{1}$ Andi Yusra ${ }^{2}$ Edi Mawardi ${ }^{3}$ \\ ${ }^{1}$ Mahasiswa Jurusan Teknik Sipil, Fakultas Teknik, Universitas Teuku Umar \\ ${ }^{2,3}$ Dosen Jurusan Teknik Sipil,Fakultas Teknik, Universitas Teuku Umar \\ Email:sustriasari.mhs@gmail.com
}

\begin{abstract}
In the world of development in Indonesia which is currently developing, the main thing that must be considered is the occupational health and safety factor, the lack of attention to the implementation of K3 can lead to an increase in work accidents in the field of construction projects. the project. K3 analysis was carried out by giving questionnaires to project implementers after which univariate and bivariate analyzes were carried out to find out the relationship between variables. The number of respondents was 40 people, from the results of the age characteristics, the most dominant was 26-35 years and the least was in the 46-55 year age category. The highest education level is in the SMA category of $42.5 \%$ and $5.0 \%$ for undergraduate education. the average tenure of workers is 0-5 years $60.0 \%$. The results of the univariate analysis showed that the frequency distribution for "Complete" answers was $52.0 \%$ for site managers, while for implementers who answered "Complete" $46.7 \%$, as well as $47.6 \%$ for supervisors. this indicates that the application of $K 3$ in the building is adequate.
\end{abstract}

Keywords: occupational health, occupational safety, univariate analysis, bivariate analysis

\begin{abstract}
Abstrak
Dalam dunia pembangunan di Indonesia yang sedang berkembang saat ini, hal utama yang harus di perhatikan ialah faktor kesehatan dan keselamatan kerja, kurangnya perhatian terhadap pelaksanaan K3 dapat menimbulkan peningkatan terhadap kecelakaan kerja di bidang proyek konstruks.Tujuan dari penelitian ini ialah untuk mengetahui penerapan K3 pada proyek tersebut. Analisis K3 dilakukan dengan memberikan kuisioner pada pelaksana proyek setelah itu dilakukan analisa univariat dan bivariate untuk mencari tahu hubungan antar variabel. jumlah responden sebanyak 40 orang, dari hasil karateristik usia didapatkan yang paling mendominasi ialah 26-35 tahun dan yang paling sedikit pada katagori usia 46- 55 tahun. Tingkat pendidikan tertinggi pada kategori SMA 42.5\% dan untuk pendidikan S1 5.0\%. rata-rata masa kerja pekerja ialah 0-5 tahun 60.0\%. Hasil analisis univariat, distribusi frekuensi untuk jawaban "Lengkap" 52.0\% untuk site manager, sedangkan untuk pelaksana yang menjawab "Lengkap” 46.7\%, begitu juga untuk pengawas $47.6 \%$. hal ini menandakan untuk penerapan K3 pada gedung tersebut sudah memadai.
\end{abstract}

Kata kunci: kesehatan kerja, keselamatan kerja, analisis univariat, analisis bivariate

\section{Pendahuluan}

Dalam dunia pembangunan di indonesia yang sedang berkembang saat ini, hal utama yang harus di perhatikan ialah faktor kesehatan dan keselamatan kerja, kurangnya perhatian terhadap pelaksanaan K3 dapat menimbulkan peningkatan terhadap kecelakaan kerja di bidang proyek konstruksi. Kesehatan dan keselamatan kerja yaitu suatu kegiatan yang wajib dan harus dilakukan dan diaplikasikan pada tiap perusahaan yang bergerak dibidang konstruksi untuk melindungi karyawannya dari resiko kecelakaan kerja yang akan menghambat jalannya kegiatan dan produktivitas pekerja.

Bidang konstruksi merupakan salah satu sektor yang mempunyai resiko tinggi dari sisi kesehatan dan keselamatan kerjanya bahkan secara umum di negara ini masih sering terabaikan. Hal ini dapat dilihat dari angka kecelakaan kerja yang masih tinggi, serta minimnya pengawasan terhadap kesehatan dan keselamatan kerja, oleh karena itu dalam mencegah kecelakaan kerja, dilakukan penerapan kesehatan dan keselamatan kerja yang baik dan benar sesui dengan peraturan-peraturan yang telah berlaku seperti Permen PUPR02-2018 tentang pedoman sistem manajemen keselamatan dan kerja (SMK3) konstruksi bidang pekerjaan umum, UU nomor 2 tahun 2017 tentang jasa konstruksi, dan lain-lain.

Didalam pekerjaan proyek bisa saja terjadi kecelakaan kerja untuk mengantisipasi terjadinya kecelakaan kerja tersebut maka diperlukannya penerapan $\mathrm{K} 3$ terutama untuk melindungi pekerja[1] sedangkan yang merujuk pada stabilitas jasmani dan mental serta emosional para pekerja itu mengacu pada keselamatan kerja.

Menurut sedarmayanti (2017), kesehatan dan keselamatan kerja ialah pengelolaan orang, mesin, bahan dan strategi yang menggabungkan tempat kerja agar pekerja tidak dirugikan. K3 tersebut mencakup dari beberapa faktor yaitu lokasi, individu (perwakilan) dan peralatan kerja.[2]

International Labour Organization (ILO), menunjukkan bahwa didalam suatu proyek terdapat banyak korban jiwa akibat kecelakaan kerja secara konsisten diseluruh dunia yang berhubungan dengan pekerjaan, ada 354.000 kasus kecelakaan kerja yang 
mengakibatkan penyakit yang diderita para pekerjanya, perusahaan setidaknya mengalami kerugian materi sebesar lebih kurang 25 triliun. Untuk di indonesia kecelakaan kerja pada proyek masih cukup tinggi. Kecelakaan kerja disetiap tahunnya terus meningkat $2,5 \%$ bahkan yang paling tinggi penimgkatannya mencapai 3,6\%.Di Indosia dalam 5 tahu terakhir kecelakaan kerja mencapai level tertinggi[3]

Peraturan yang diberlakukan untuk pelaksanaan kesehatan keselamatan kerja dapat dijadikan patokan untuk konsultan, kontraktor, serta tenaga kerja agar dapat meminimalisir dan menghindari kecelakaan kerja. Akan tetapi, fakta dilapangan dalam penerapan kesehatan keselamatan kerja, ada beberapa perusahaan konstruksi yang masih belum menerapkan kesehatan keselamatan kerja, hal ini dapat menimbulkan resiko yang sangat tinggi serta cenderung dapat menimbulkan kecelakaan kerja pada saat di proyek. Selain itu pada saat tidak diterapkan kesehatan keselamatan kerja juga dapat merusak sistem pelaksanaan kesehatan keselamatan kerja yang berlaku, serta dapat menimbulkan kerugian yang ada di perusahaan tersebut.

Factor - factor terkait keselamatan, kesehatan kerja (K3) sangat berpengaruh terhadap prestasi suatu proyek,, sehingga harus dipikirkan secara matang. . Pengabaian factor- factor ini telah terbukti membawa tingkat kecelakaan kerja yang tinggi pada proyek tersebut. Hal ini akan menambah biaya perlindungan kerja dan mempengaruhi pelaksanaan proyek. Oleh karena itu, pada saat melakukan pekerjaan pembangunan, perlu dilaksanakan kerangka kerja sistem manajemen keselamatan dan kesehatan kerja (SMK3) di lokasi kerja, di mana yang berkaitan dengan masalah keamanan dan kesehatan juga penting untuk pengaturan dan pengendalian proyek[4]

Peraturan yang mengatur tentang kesehatan dan keselamatan kerja (K3) pada bidang konstruksi ialah UU Nomor 1 Tahun 1970 tentang keselamatan kerja. Peraturan Menteri Tenaga Kerja Republik Indonesia Nomor PER.05/MEN/1996 juga mengatur tentang sistem manajemen keselamatan dan kesehatan kerja, dan Keputusan Menteri Tenaga Kerja Republik Indonesia Nomor. KEP/96/M/BW/1997 tentang Inspeksi Keselamatan dan Kesehatan Kerja[5]

Penelitian terdahulu sudah di analisis oleh Chaira 2018, yang berjudul Evaluasi Penerapan Keselamatan dan Kesehatan Kerja Pada Gedung Perawatan Jiwa RSUD Nagan Raya, mengungkapkan bahwa dihasil penelitian pada proyek tersebut menunjukkan rendahnya penerapan keselamatan, kesehatan kerja pada proyek yang bersangkutan. Hal tersebut disebabkan karena rendahnya tingkat pemahaman tentang manajemen Keselamatan, kesehatan kerja oleh Site manager, Pelaksana, Pengawas serta para Pekerja, sehingga orang yang bekerja di proyek tersebut tidak mendapatkan pengetahuan tentang kesehatan keselamatan kerja[6]

\section{Metodelogi}

Analisis ini diambil pada proyek pembangunan gedung perpustakaan kabupaten aceh jaya, penelitian ini dimulai dengan pengumpulan informasi dimana dalam penelitian ini dipakai data primer yaitu data yang didapat dari responden dengan melakukan wawancara, observasi dan pembagian kuisioner secara langsung. Sedangkaan data sekunder diperoleh dari Jurnal, artikel buku dan juga dari data perusahaan yang bersangkutan.. Variabel yang dipakai dalam analisis ini yaitu variabel bebes (independent) dan variabel terikat (dependent). Variabel bebas ialah variabel yang menyebabkan terjadinya perubahan pada variabel dependen (variabel terikat). Dalam penelitian digunakan empat variabel independen yaitu $\mathrm{X} 1$ (site manager), X2 (pelaksana), X3 (pengawas) dan X4 (pekerja) dan untuk Variabel dependentnya ialah penerapan keselamatan, kesehatan kerja pada proyek konstruksi (Y).

a. Pengamatan (observasi)

Observasi yaitu cara yang dipakai untuk mendapatkan informasi dengan melakukan pengamatan dan mencatat semua objek yang akan diteliti. Pada metode observasi dilakukan pengamatan tentang kesehatan keselamatan kerja yang ada pada proyek Pembangunan Gedung Perpustakaan Kabupaten Aceh Jaya.

b. Interview (wawancara) Interview yaitu cara yang dipakai untuk mendapatkan informasi dengan mengajukan pertanyaan dan jawaban langsung dari narasumber yang berkaitan dengan objek penelitian. Pada metode wawancara dilakukan penyebaran kuisioner yang telah disiapkan dan kemudian disebarkan kepada orang-orang proyek.

c. Dokumentasi

Dokumentasi adalah cara yang dipakai untuk mendapatkan informasi dengan cara mengambil gambar di lokasi proyek

\subsection{Analisi data}

Didalam penelitian ini menggunakan 2 analisis yaitu bivariat dan univariate digunakan untuk menganalisis keterkaitan antara variabel- variabel tersebut antara lain penerapan keselamatan kesehatan kerja sebagai variabel terikat dan factor - factor yang 
mempengaruhi keselamatan kesehatan kerja sebagai variabel bebas nya pada pembangunan tersebut. Analisis bivariate digunakan untuk mendapatkan hubungan antara variabel bebas dengan variabel terikat melalui uji chi-square. Untuk uji Chi-square menggunakan rumus (Hastono,2007) sebagai berikut:

$x^{2}-\sum \frac{(0-E)}{E}$

Dimana:

$\mathrm{X}^{2}=$ Chi-square

$\mathrm{O}=$ Nilai Observasi (nilai yang diamati)

$\mathrm{E}=$ Nilai Expected (nilai harapan)

Untuk pengujian chi square aturan yang dipakai yaitu:

a. Bila tabel $2 \times 2$ terdapat nilai exact test kurang dari 5, maka digunakan fisher's exact test.

b. Bila tabel $2 \times 2$ bertemu hasil exact test lebih dari 5, maka digunakan continuity correction

c. Apabila tabel lebih dari $2 \times 2$, maka digunakan pearson chi-square.[6]

\section{Hasil dan pembahasan}

Ada beberapa terlibat dalam analisis ini yaitu site manager, pelaksana, pengawas dan pekerja yang terjun dalam proyek gedung perpustakaan kabupaten aceh jaya. Jumlah seluruh responden yang terlibat ialah sebanyak 40 orang.

\subsection{Hasil}

Factor - factor yang dipakai dalam analisis ini didapat dengan cara mengoreksi analisa terdahulu dan menyesuaikan dengan keadaan di lapangan pada analisis ini menggunakan 4 variabel bebas yakni site manager, pelaksana, pengawas dan pekerja sedangkan yang menjadi variabel Y ialah penerapan keselamatan kesehatan kerja dipembangunan gedung tersebut.

Dari Hasil pembagian Kuisioner dan analysis data, maka hasil yang diperoleh di sajikan kedalam bentuk sistematik yaitu:
a. Karakteristik responden
b. Profil responden
c. Analisis univariat
d. Analisis bivariate

a. Karakteristik responden

Jumlah responden yang mengisi kuisioner pada Pembangunan Gedung Perpustakaan Kabupaten Aceh Jaya dapat dilihat pada table berikut.

Tabel 1.1 Jumlah responden berdasarkan usia

Usia

\begin{tabular}{|c|c|c|c|c|c|}
\hline & & $\begin{array}{c}\text { Frekue } \\
\text { nsi }\end{array}$ & $\begin{array}{c}\text { persen } \\
\text { tase }\end{array}$ & $\begin{array}{c}\text { Parsentas } \\
\text { e yang } \\
\text { valid }\end{array}$ & $\begin{array}{l}\text { Persentas } \\
\text { e } \\
\text { kumulatif }\end{array}$ \\
\hline & $16-25$ & 13 & 32.5 & 32.5 & 32.5 \\
\hline & $26-35$ & 15 & 37.5 & 37.5 & 70.0 \\
\hline $\begin{array}{l}\mathrm{Va} \\
\end{array}$ & $36-45$ & 6 & 15.0 & 15.0 & 85.0 \\
\hline 110 & $46-55$ & 6 & 15.0 & 15.0 & 100.0 \\
\hline & Total & 40 & 100.0 & 100.0 & \\
\hline
\end{tabular}

Dilihat dari tabel $\mathbf{1 . 1}$ Responden yang mendominasi pada analisis ini menurut usia dapat dikatagorikan dari usia 26-35 tahun ada 15 orang persentasenya $37,5 \%$ dan yang paling sedikit persentasenya dikategorikan dari usia 46-55 tahun yaitu 6 oramg didapat persentasenya 15,0\%.

Tabel 1.2 Jumlah responden berdasarkan tingkat pendidikan

\begin{tabular}{|c|c|c|c|c|c|}
\hline \multicolumn{6}{|c|}{ Pendidikan } \\
\hline & & $\begin{array}{c}\text { Frekue } \\
\text { nsi }\end{array}$ & $\begin{array}{l}\text { Perse } \\
\text { ntase }\end{array}$ & $\begin{array}{c}\text { Persenta } \\
\text { se yang } \\
\text { valid }\end{array}$ & $\begin{array}{c}\text { Persen } \\
\text { kumulatif }\end{array}$ \\
\hline \multirow{6}{*}{$\begin{array}{l}\text { Val } \\
\text { id }\end{array}$} & S1 & 2 & 5.0 & 5.0 & 5.0 \\
\hline & D3 & 1 & 2.5 & 2.5 & 7.5 \\
\hline & SMA/ & 17 & 42.5 & 42.5 & 50.0 \\
\hline & SMP & 12 & 30.0 & 30.0 & 80.0 \\
\hline & SD & 8 & 20.0 & 20.0 & 100.0 \\
\hline & Total & 40 & 100.0 & 100.0 & \\
\hline
\end{tabular}

Dilihat dari tabel $\mathbf{1 . 2}$ Responden yang mendominasi menurut tingkat pendidikan,SMA ada 17 orang persentasenya $42,5 \%$.sedangkan pendidikan ditingkat sarjana setara S1 ada 2 orang dengan persentasenya $5,0 \%$ dan untuk yang pendidikannya D3 hanya ada 1 orang dengan persentase 2,5

Tabel 1.3 jumlah responden berdasarkan masa kerja

Masa_kerja 


\begin{tabular}{|c|c|c|c|c|}
\hline $\begin{array}{l}\text { Masa } \quad \text { kerja } \\
\text { (Tahun) }\end{array}$ & $\begin{array}{l}\text { Freku } \\
\text { ensi }\end{array}$ & $\begin{array}{l}\text { Perse } \\
\text { ntase }\end{array}$ & $\begin{array}{c}\text { Persent } \\
\text { ase } \\
\text { yang } \\
\text { valid }\end{array}$ & $\begin{array}{c}\text { Persenta } \\
\text { se } \\
\text { Kumulat } \\
\text { if }\end{array}$ \\
\hline $0-5$ & 24 & 60.0 & 60.0 & 60.0 \\
\hline $6-10$ & 12 & 30.0 & 30.0 & 90.0 \\
\hline $\begin{array}{ll}\text { Val } & 11-15\end{array}$ & 2 & 5.0 & 5.0 & 95.0 \\
\hline Diatas 15 & 2 & 5.0 & 5.0 & 100.0 \\
\hline Total & 40 & 100.0 & 100.0 & \\
\hline
\end{tabular}

Dilihat dari tabel 1.3, Dilihat dari tabel 1.3, jumlah responden yang terlibat pada proyek ini diketahui bahwa masa kerja rata-ratanya adalah 0-5 tahun dengan $60,0 \%$ dan paling sedikit adalah diatas 15 tahun dengan 5,0\%.

\section{b. Profil responden}

Jumlah responden yang berpartisipasi dalam menyelesaikan polling pada penelitian ini adalah 40 individu, dari variabel bebas dan variabel terikat. Kemudian didapatkan hasil dari rata-rata responden cukup memahami tentang bahaya kecelakaan kerja yang bisa saja terjadi pada dirinya selama menyelesaikan proyek.

c. analisi univariat

Untuk mengetahui hubungan antara variabel dilakukan analisis bivariate,sebelum itu dilakukan anlisis univariat menggunakan table distribusi pada tiap-tiap variabel yang diteliti.

Tabel 2.1 Distribusi frekuensi jawaban dari site manager

\section{Site_manager}

\begin{tabular}{|l|r|r|r|r|}
\hline & $\begin{array}{r}\text { Freku } \\
\text { ensi }\end{array}$ & $\begin{array}{r}\text { Perse } \\
\text { ntase }\end{array}$ & $\begin{array}{c}\text { Persent } \\
\text { ase } \\
\text { yang } \\
\text { valid }\end{array}$ & $\begin{array}{c}\text { Persenta } \\
\text { se } \\
\text { kumulati } \\
\text { f }\end{array}$ \\
\hline & 6 & 24.0 & 24.0 & 24.0 \\
Val Lengkap \\
id $\begin{array}{l}\text { Sangat } \\
\text { lengkap }\end{array}$
\end{tabular}

Berdasarkan table 2.1, distribusi frekuensi untuk 25 pernyataan yang terlampir pada kuesioner,yang menjawab "lengkap'mendapatkan nilai $52.0 \%$ atau dapat peluang 13 kali muncul dalam jawaban site manager dan yang menjawab "Cukup" adalah 24.0\% atau site manager memiliki peluang 6 kali menjawab site manager.

Tabel 2.2 Distribusi frekuensi jawaban pelaksana

\begin{tabular}{|c|c|c|c|c|c|}
\hline \multicolumn{6}{|c|}{ Pelaksana } \\
\hline & & Frekunsi & $\begin{array}{c}\text { Persent } \\
\text { ase }\end{array}$ & $\begin{array}{l}\text { Persentase } \\
\text { yang valid }\end{array}$ & $\begin{array}{l}\text { Persentase } \\
\text { kumulatif }\end{array}$ \\
\hline & cukup & 3 & 20.0 & 20.0 & 20.0 \\
\hline & lengkap & 7 & 46.7 & 46.7 & 66.7 \\
\hline & $\begin{array}{l}\text { sangat } \\
\text { lengkap }\end{array}$ & 5 & 33.3 & 33.3 & 100.0 \\
\hline & Total & 15 & 100.0 & 100.0 & \\
\hline
\end{tabular}

Berdasarkan table 2.2 distribusi frekuensi untuk 15 pernyataan yang terlampir pada kuisioner yang menjawab "Lengkap" mendapatkan nilai $46.7 \%$ atau dapat peluang7 kali muncul dalam jawaban pelaksana, dan yang menjawab "Cukup" adalah $20.0 \%$ atau 3 kali muncul dan untuk jawaban "Sangat Lengkap" yaitu $33.3 \%$ atau dari jawaban responden memiliki peluang 5 kali.

Tabel 2.3 Distribusi frekuensi jawaban pengawas Pengawas 


\begin{tabular}{|r|r|r|r|r|}
\hline & $\begin{array}{r}\text { Freku } \\
\text { ensi }\end{array}$ & $\begin{array}{r}\text { perse } \\
\text { ntase }\end{array}$ & $\begin{array}{c}\text { Persent } \\
\text { ase } \\
\text { yang } \\
\text { valid }\end{array}$ & $\begin{array}{c}\text { Persenta } \\
\text { se } \\
\text { kumulati } \\
\text { f }\end{array}$ \\
\hline Cukup & 7 & 33.3 & 33.3 & 33.3 \\
Val Lengkap \\
id $\begin{array}{l}\text { sangat } \\
\text { lengkap }\end{array}$
\end{tabular}

Berdasarkan tabel 2.3 distribusi frekuensi untuk 21 pernyataan yang terlampir pada kuisioner, yang menjawab "Lengkap" mendapatkan nilai $47.6 \%$ atau dapat peluang 10 kali dalam jawaban responden, jawaban "Cukup" yaitu $33.3 \%$ atau jawaban responden berpeluang 7 kalil, jawaban "Sangat Lengkap" mendapat nilai $19.0 \%$ atau 4 kali muncul dalam jawaban responden.

Tabel 2.4 Distribusi frekuensi jawaban pekerja (37 orang)

\begin{tabular}{|c|c|c|c|c|c|}
\hline \multicolumn{6}{|c|}{ Pekerja } \\
\hline & & $\begin{array}{c}\text { Freku } \\
\text { ensi }\end{array}$ & $\begin{array}{c}\text { Persent } \\
\text { ase }\end{array}$ & $\begin{array}{c}\text { Persent } \\
\text { ase } \\
\text { yang } \\
\text { valid }\end{array}$ & $\begin{array}{l}\text { Persentase } \\
\text { kumulatif }\end{array}$ \\
\hline \multirow{16}{*}{$\begin{array}{l}\text { Vali } \\
\text { d }\end{array}$} & 120 & 1 & 3.3 & 3.3 & 3.3 \\
\hline & 122 & 1 & 3.3 & 3.3 & 6.7 \\
\hline & 123 & 1 & 3.3 & 3.3 & 10.0 \\
\hline & 125 & 1 & 3.3 & 3.3 & 13.3 \\
\hline & 129 & 1 & 3.3 & 3.3 & 16.7 \\
\hline & 130 & 1 & 3.3 & 3.3 & 20.0 \\
\hline & 131 & 1 & 3.3 & 3.3 & 23.3 \\
\hline & 133 & 2 & 6.7 & 6.7 & 30.0 \\
\hline & 134 & 1 & 3.3 & 3.3 & 33.3 \\
\hline & 135 & 1 & 3.3 & 3.3 & 36.7 \\
\hline & 136 & 1 & 3.3 & 3.3 & 40.0 \\
\hline & 137 & 5 & 16.7 & 16.7 & 56.7 \\
\hline & 138 & 3 & 10.0 & 10.0 & 66.7 \\
\hline & 139 & 1 & 3.3 & 3.3 & 70.0 \\
\hline & 140 & 2 & 6.7 & 6.7 & 76.7 \\
\hline & 141 & 1 & 3.3 & 3.3 & 80.0 \\
\hline
\end{tabular}

\begin{tabular}{|r|r|r|r|r|}
\hline 142 & 2 & 6.7 & 6.7 & 86.7 \\
143 & 1 & 3.3 & 3.3 & 90.0 \\
144 & 2 & 6.7 & 6.7 & 96.7 \\
146 & 1 & 3.3 & 3.3 & 100.0 \\
Total & 30 & 100.0 & 100.0 & \\
\hline
\end{tabular}

Berdasarkan table 2.4 analisis terhadap 37 orang pekerja untuk 30 pernyataan dapat dikatakan valid.

d. Analisis bivariate

Hubungan antar variabel bebas dan variaber terikat dapat dilihat setelah melakukan analisis bivariate dengan menggunkan uji Chi-Square

Tabel 3.1 Distribusi kolerasi hubungan

Correlations

\begin{tabular}{|c|c|c|c|c|c|}
\hline & & $\begin{array}{c}\text { Site } \\
\text { manager }\end{array}$ & Pelaksana & Pengawas & Pekerja \\
\hline \multirow{7}{*}{$\begin{array}{l}\text { Site } \\
\text { manage } \\
r\end{array}$} & Pearson & & & & \\
\hline & Correlati & 1 & .018 & .323 & .102 \\
\hline & on & & & & \\
\hline & Sig. (2- & & .949 & .153 & .629 \\
\hline & $\mathrm{N}$ & 25 & 15 & 21 & 25 \\
\hline & Pearson & & & & \\
\hline & Correlati & .018 & 1 & -.200 & .215 \\
\hline \multirow{5}{*}{$\begin{array}{l}\text { Pelaksa } \\
\text { na }\end{array}$} & on & & & & \\
\hline & $\begin{array}{l}\text { Sig. } \\
\text { tailed) }\end{array}$ & .949 & & .474 & .441 \\
\hline & $\mathrm{N}$ & 15 & 15 & 15 & 15 \\
\hline & Pearson & & & & \\
\hline & Correlati & .323 & -.200 & 1 & -.213 \\
\hline \multirow{5}{*}{$\begin{array}{l}\text { Pengaw } \\
\text { as }\end{array}$} & on & & & & \\
\hline & $\begin{array}{l}\text { Sig. } \\
\text { tailed) }\end{array}$ & .153 & .474 & & .354 \\
\hline & $\mathrm{N}$ & 21 & 15 & 21 & 21 \\
\hline & Pearson & & & & \\
\hline & Correlati & .102 & .215 & -.213 & 1 \\
\hline \multirow{3}{*}{ Pekerja } & on & & & & \\
\hline & $\begin{array}{l}\text { Sig. } \\
\text { tailed) }\end{array}$ & .629 & .441 & .354 & \\
\hline & $\mathrm{N}$ & 25 & 15 & 21 & 30 \\
\hline
\end{tabular}

Tabel 3.2 Tabel tes statistic 


\begin{tabular}{|l|c|c|c|c|}
\hline & $\begin{array}{c}\text { Site } \\
\text { manag } \\
\text { er }\end{array}$ & $\begin{array}{c}\text { pelaksa } \\
\text { na }\end{array}$ & $\begin{array}{c}\text { pengaw } \\
\text { as }\end{array}$ & $\begin{array}{c}\text { Pekerj } \\
\text { a }\end{array}$ \\
\hline $\begin{array}{l}\text { Chi- } \\
\text { square }\end{array}$ & $2.890^{\mathrm{a}}$ & $2.126^{\mathrm{b}}$ & $.686^{\mathrm{c}}$ & $\begin{array}{c}12.00 \\
0^{\mathrm{d}}\end{array}$ \\
\hline Df & 2 & 2 & 2 & 10 \\
\hline $\begin{array}{l}\text { Asym.S } \\
\text { ig }\end{array}$ & .236 & .345 & .710 & .285 \\
\hline
\end{tabular}

Berdasarkan table 3.2 dapat dilihat untuk nilai yang paling tinggi ialah 12.000 yang didapatkan oleh pekerja dan untuk nilai terendahnya didapatkan oleh pengawas, dan untuk site manager mendapatkan nilai 2.890, pelaksana 2.126, dari hasil analisa bivariate dengan pengujian chi square hal itu menunjukkan bahwa nilai-nilai tersebut lebih besar dari nilai lavel of significance (a) 0,5 yang berarti bahwa hipotesis penelitian ini bisa diterima dan tidak ditemukan perbedaan pada setiap variabel $\mathrm{X} 1, \mathrm{X} 2, \mathrm{X} 3$ dan $\mathrm{X} 4$ terhadap penerapan kesehatan dan keselamatan kerja.

\subsection{Pembahasan}

Dari hasil analisis implementasi untuk penerapan kesehatan dan keselamatan kerja untuk 40 orang responden dari hasil penyebaran kuesioner didapatkan karakteristik responden pada usia yang paling mendominasi pada penelitian ini ialah kategori usia 26-35 tahun berjumlah 15 orang dengan nilai 37,5\% sedangkan untuk yang paling rendah terdapat pada kategori usia 46-55 tahun berjumlah 6 orang didapat persentase 15,0\%.Dan untuk karakteristik pada tingkat pendidikan untuk hasil tertinggi terdapat pada kategori pendidikan SMA berjumlah 17 orang dengan nilai $42,5 \%$ dan untuk kategori S1 berjumlah 2 orang dengan nilai $5,0 \%$ sedangkan pada rata-rata masa kerja pada pekerja ialah 0-5 tahun dengan nilai 60,0\%.Dan yang masa kerjanya diatas 15 tahun sebanyak 2 orang dengan nilai 5,0\%.Berdasarkan persentase yang didapat untuk alisis univariat pada jawaban lengkap ialah $52,0 \%$ pada site manager.Sedangkan untuk jawaban lengkap yang dijawab oleh pelaksana adalah $46,7 \%$ begitu juga untuk pengawas $47,6 \%$ hal ini menandakan memadainya penerapan keselamatan dan kesehatan kerja pada pembangunan tersebut. Berdasarkan hasil yang diperoleh dari tabel 4.1 dan 4.2 dimana dapat dilihat variabel $\mathrm{X}$ dan $\mathrm{Y}$ dari hasil analisis bivariate digunakan uji Chi Square mendapatkan hasil terendah 0,686 dari jawaban pengawas, untuk hasil tertinggi didapat pada pekerja sebesar 12.000,hal ini menunjukan pada pekerja telah melakukan penerapan keselamatan kesehatan kerja yang cukup.

\section{Kesimpulan}

Dapat ditarik kesimpulan hasil dari analisa dan pembahasan tersebut sebagai berikut.

1. Dalam penelitian ini dari karaterristik responden dari usia 26-35 tahun berjumlah 15 orang dengan persentase $37,5 \%$ dan yang paling sedikit dari kategori usia 46-55 tahun dengan jumlah 6 orang dengan persentase $15,0 \%$. Ditingkat pendidikan tertinggi ada pada kategori SMA berjumlah 17 orang dengan $42,5 \%$ dan untuk kategori pendidikan sarjana setara S1 berjumlah 2 orang dengan persentase $5,0 \%$. Untuk masa kerja ratarata pekerja dalah 0-5 tahun sebanyak 24 orang dengan $60 \%$ dan untuk masa kerja diatas 15 tahun sebanyak 2 orang dengan $5,0 \%$ persentase.

2. Berdasarkan analisis univariat untuk distribusii frekuensi pada shif manager untuk jawaban lengkap ialah $52,0 \%$ sedangkan untuk jawaban lengkap pada pelaksana adalah $46,7 \%$ begitu juga untuk pengawas $46,7 \%$

\section{Daftar pustaka}

[1] S. D. R. Sari, H. Brimantyo, and E. A. Susilo, "PENGARUH KESELAMATAN DAN KESEHATAN KERJA TERHADAP KEPUASAN KERJA (Studi pada Karyawan Bagian Pabrikasi PG Kebon Agung Malang) Skolastika Dian Rosita Sari, Eko Agus Susilo, Harril Brimantyo," J. Bisnis dan Manaj., vol. 4, no. 2, pp. 121-128, 2017, [Online]. Available:

http://jurnal.unmer.ac.id/index.php/jbm/articl e/view/1705.

[2] V. K. Nan Wangi, "Dampak Kesehatan Dan Keselamatan Kerja, Beban Kerja, Dan Lingkungan Kerja Fisik Terhadap Kinerja," J. Manaj. Bisnis, vol. 7, no. 1, pp. 40-50, 2020, doi: 10.33096/jmb.v7i1.407.

[3] A. S. W. Dian Putri Maharani, "Pengetahuan, Sikap, Kebijakan K3 Dengan Penggunaan Alat Pelindung Diri Di Bagian Ring Spinning Unit 1," JHE (Journal Heal. Educ., vol. 2, no. 1, pp. 33-38, 2017, doi: 10.15294/jhe.v2i1.18823.

[4] R. Maretnowati, A. Azizi, and S. Anjarwati, "ANALISIS PELAKSANAAN KESELAMATAN DAN KESEHATAN KERJA ( $\mathrm{K} 3 \quad$ ) PADA PROYEK PEMBANGUNAN GEDUNG K UNIVERSITAS MUHAMMADIYAH PURWOKERTO THE ANALYSIS OF OCCUPATIONAL SAFETY AND HEALTH IMPLEMENTATION ( OSH ) ON THE CONSTRUCTION PROJECT OF," vol. 1, no. 2, pp. 69-76, 2020. 
[5] A. S. Rudjito, "Analisis penerapan keselamatan dan kesehatan kerja pada proyek gedung di jawa tengah," 2006.

[6] Z. Chaira, "Evaluasi Penerapan Keselamatan dan Kesehatan Kerja Pada Gedung Perawatan Jiwa RSUD Nagan Raya," vol. 4, no. 2, 2018. 